\title{
Pangenomic type III effector database of the plant pathogenic Ralstonia spp.
}

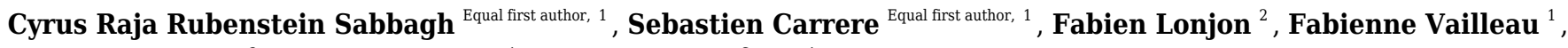 \\ Alberto P Macho ${ }^{3}$, Stephane Genin ${ }^{1}$, Nemo Peeters ${ }^{\text {Corresp. } 1}$ \\ 1 LIPM, Université de Toulouse, INRA, CNRS, Castanet-tolosan, France \\ 2 Department of Cell \& Systems Biology, University of Toronto, Toronto, Canada \\ 3 Shanghai center for plant stress biology, CAS Center for Excellence in Molecular Plant Sciences, Shanghai Institutes of Biological Sciences, Chinese \\ Academy of Sciences, Shanghai, China \\ Corresponding Author: Nemo Peeters \\ Email address: nemo.peeters@inra.fr
}

Background. The bacterial plant pathogenic Ralstonia species belong to the betaproteobacteria class and are soil-borne pathogens causing vascular bacterial wilt disease, affecting a wide range of plant hosts. These bacteria form a heterogeneous group considered as a "species complex"," gathering three newly defined species. Like many other Gram negative plant pathogens, Ralstonia pathogenicity relies on a type III secretion system, enabling bacteria to secrete/inject a large repertoire of type III effectors into their plant host cells. T3Es are thought to participate in generating a favorable environment for the pathogen (countering plant immunity and modifying the host metabolism and physiology). Methods. Expert genome annotation, followed by specific type III-dependent secretion, allowed us to improve our Hidden-Markov-Model and Blast profiles for the prediction of type III effectors. Results. We curated the T3E repertoires of 12 plant pathogenic Ralstoniastrains, representing a total of 12 strains spread over the different groups of the species complex. This generated a pangenome repertoire of 102 T3E genes and 16 hypothetical T3E genes. Using this database, we scanned for the presence of T3Es in the 155 available genomes representing 140 distinct plant pathogenic Ralstonia strains isolated from different host plants in different areas of the globe. All this information is presented in a searchable database. A presence/absence analysis, modulated by a strain sequence/gene annotation quality score, enabled us to redefine core and accessory T3E repertoires. 


\section{Pangenomic Type III effector database of the plant pathogen}

\section{Ralstonia}

4

5

6

8

Corresponding Author:

Nemo Peeters ${ }^{1}$

LIPM, INRA CS52627, Chemin de borde Rouge, Auzeville, 31326 Castanet-Tolosan, France Email address: nemo.peeters@inra.fr

\section{Abstract}

Background. The bacterial plant pathogenic Ralstonia species belong to the beta-proteobacteria class and are soil-borne pathogens causing vascular bacterial wilt disease, affecting a wide range of plant hosts. These bacteria form a heterogeneous group considered as a "species complex"," gathering three newly defined species. Like many other Gram negative plant pathogens, Ralstonia pathogenicity relies on a type III secretion system, enabling bacteria to secrete/inject a large repertoire of type III effectors into their plant host cells. T3Es are thought to participate in generating a favorable environment for the pathogen (countering plant immunity and modifying the host metabolism and physiology). 
31 Methods. Expert genome annotation, followed by specific type III-dependent secretion, allowed 32 us to improve our Hidden-Markov-Model and Blast profiles for the prediction of type III 33 effectors.

34

35

36

37

38

39

40

41

42

43

44

45

46

47

48

49

50

51

52

53

54

55

56

57

58

59 Plant pathogenic Xanthomonas spp., and animal pathogens like Escherichia spp., Shigella spp.

60 or Yersinia spp. have around 30 T3Es per strain (Dong et al. 2015; Schwartz et al. 2015).

61 Classically known strains of Pseudomonas spp. have also around 30-40 T3Es (Wei et al. 2015),

Results. We curated the T3E repertoires of 12 plant pathogenic Ralstonia strains, representing a total of 12 strains spread over the different groups of the species complex. This generated a pangenome repertoire of $102 \mathrm{~T} 3 \mathrm{E}$ genes and 16 hypothetical T3E genes. Using this database, we scanned for the presence of T3Es in the 155 available genomes representing 140 distinct plant pathogenic Ralstonia strains isolated from different host plants in different areas of the globe. All this information is presented in a searchable database. A presence/absence analysis, modulated by a strain sequence/gene annotation quality score, enabled us to redefine core and accessory T3E repertoires.

\section{Introduction}

Plant pathogenic Ralstonia species (Peeters et al. 2013b) were ranked among the 10 most important plant bacterial pathogens (Mansfield et al. 2012). These soil-resident bacteria are 9 indeed important, as they affect many different plant species, ranging from solanaceous crops to 0 other important crops like banana and peanut, in different parts of the world. Recently, new plant 1 species have been found to be infected and present symptoms of bacterial wilt, like blueberry 52 shrubs in Florida, USA (Bocsanczy et al. 2019), ornamental roses in the Netherlands (Bergsma5 Vlami et al. 2018), or pumpkin in China (She et al. 2017). This bacterium has one of the largest 54 known repertoires of T3Es among all plant or animal pathogenic bacteria. The type III secretion 5 system (T3SS) of Gram negative phytopathogenic bacteria is essential for virulence, and Type 6 III-secreted effectors (T3Es hereafter) have been found to contribute in many different and 57 sometimes redundant manners to the fitness of the bacterium in interaction with its host (Buttner 58 2016). 
62 with some rare cases of up to 50 T3Es in a given strain (Dillon et al. 2019). It was reported that

63 Legionella spp. can secret in their host cells up to 300 effectors type IV effectors) (Gomez-

64 Valero et al. 2019). Plant pathogenic Ralstonia spp. have between 46 to 71 T3Es (Peeters et al. 65 2013a).

66 In this work, we curated the genome of 2 new phylotype I strains bringing the total number of

67 curated strains to 12 plant pathogenic Ralstonia strains, representing the known diversity of

68 phylotypes (Wicker et al. 2012), more recently subdivided into three species (Safni et al. 2014).

69 This generated new and updated profiles for the prediction of 102 Rips ("Ralstonia injected

70 Proteins") and 16 hypothetical Rips, to be compared with the previous 94 Rips and 16

71 hypothetical Rips (Peeters et al. 2013a). Two hypothetical Rips from the reference strain

72 CMR15, Psi07, and GMI1000 were experimentally confirmed as being bona fide Rips (and were 73 named RipBM and RipBO).

74 The new and improved prediction profiles were used to analyze the effector repertoires of the

75155 genomic sequences available in genbank. This dataset represents 140 different strains spread 76 over the three newly defined species: 54 Ralstonia solanacearum stains(16 Phylotype IIA and

7738 Phylotype IIB strains), 59 Ralstonia pseudosolanacearum strains(57 Phylotype I and 2

78 Phylotype III strains) and 27 Ralstonia syzygii strains(27 Phylotype IV strains). The prediction of 79 all 118 Rips (including hypothetical Rips) over the whole dataset of 155 genomes/140 different 80 strains is available as a browsable database, enabling direct comparisons between strain 81 repertoires, from presence/absence tables to multiple alignments of DNA and protein sequences. 82 This dataset was then further analyzed to evaluate how conserved the Rips are among these 140 83 strains. This analysis took into account the host of isolation as a strong (but limited) host cue, or 84 the phylogenetic group, to identify host or kinship repertoire conservation.

\section{Materials \& Methods}

89 
91 The genbank genome data repository was scanned for the presence of complete genome

92 sequences of Ralstonia species complex strains. The total number of genomes gathered was 155 , 93 with some strains sequenced multiple times by different research groups, yielding sequence data

94 for 140 distinctive strains. Owing to the fact that for a same strain different isolates could be

95 slightly different, and also to the fact that sequence quality is important for gene repertoire 96 completeness, we decided to keep all strain duplicates (in the database duplicates and triplicates are indicated as "-2" and "-3", respectively). Strains in duplicates are the following: FJAT-1458, FJAT-91, PSS4, CFBP2957, K60, CFBP6783, IBSBF1503, IPO1609, Po82, and UW163. Molk2 strain was present in the database with three independent sequence files, and UW551 with four independent sequence files. Table S1 contains all the available data on the 155 genome files. Whenever available, data for the following fields were also recorded : strain synonym; pubmed ID of reference articles; Species name (Safni et al. 2014); Phylotype; Geographical origin (isolation site); Plant isolated from; Genome assembly size; Assembly score; Number of contigs; Number of scaffolds; Bioproject. Figure S1 provides a mutS phylogeny (Wicker et al. 2012) indicating the strain relatedness.

106

107

\section{Genome quality}

Some genome sequences deposited by their authors were of insufficient quality to be included in the Refseq database. Among the different quality critera used by refseq one can find low contig N50, low gene count, or absence of essential rRNA, robosomal proteins and tRNA genes; for a complete list of criteria see https:/www.ncbi.nlm.nih.gov/assembly/help/anomnotrefseq/. This is the case for the genomic entries FJAT-452, FJAT-462, T110, T12, T25 and UW700. These sequences were left on the complete database but were excluded for the further analysis in this work.

115 We then devised an assembly score in order to sort all the strains and to distinguish draft from complete and "polished" genomes. This score is $\log _{10}$ (assembly size/number of contigs, with contigs being the $\mathrm{N}$-free scaffolds or assembled pseudomolecules that were spliced by us on $\mathrm{N}$ stretches), and is a good general score to assess the overall completeness of the genome sequence. One exception to this is the strain CFBP2957, with a high score (6.287), but for which only the chromosome was available (and not the megaplasmid, see the bipartite nature of plant 
121 pathogenic Ralstonia genomes (Salanoubat et al. 2002)), and thus artificially increased the 122 quality score.

123 We then used a known metric for genome quality called BUSCO ("Benchmarking Universal 124 Single-Copy Orthologs") based on the comparison of predicted ORF (we used PRODIGAL 125 (Hyatt et al. 2010)) with an adequate set of conserved single-gene orthologs (Waterhouse et al. 126 2017). We used the beta-proteo-bacteria lineage derived set of 582 BUSCO genes. The 127 completeness metric $(\mathrm{C} \%)$ represents the presence and not-frameshifted BUSCO ORFs in a 128 given strain genome. This data was added in Table S1. This metric was not sufficient to remove 129 the poorly sequenced genomes as 5 out of the 6 genomes excluded from the Refseq database had 130 a high completeness score (T12: 98.8\%; T110: 98.6\%; UW700: 98.6\%; FJAT-462: 98.6\%; T25: 131 96.2\%).

132 Neither the assembly score, the BUSCO metric (nor a combination of both) was efficient enough 133 to weed out poorly sequenced genomes. We thus felt the need to indirectly rate the gene 134 annotation and prediction if it were to be further used in T3E repertoire comparisons. This is why 135 we decided to generate two stringency cutoffs using the total T3E gene prediction performed by 136 our prediction pipeline: for each strain the content in multicopy paralogous genes ("MULTI"), 137 the single defined genes ("OK"), the frame-shifted genes ("FS"), and the pseudogenes ("PG"), 138 were computed for the 102 T3Es. We applied two levels of stringency. For "stringency 1", we 139 kept only the strains for which the total number of pseudogenes plus frame-shifted genes is lower 140 than 10: $(\mathrm{PG}+\mathrm{FS})<10$; this yielded a total of 123 genomes corresponding to 114 different 141 strains. For "stringency 2", we only kept the strains that also had more than 50 T3Es in total ; 142 this yielded to a set of 88 genomes corresponding to 84 different strains. Table S1 contains two 143 columns identifying the 123 "stringency 1" and 88 "stringency 2" strains.

144 This "stringency" ranking is an artificial cutoff, but we believe this is a valid method to further 145 compare the complete gene repertoires. The two strains T110 and UW700 have high genome 146 assembly scores (6.45 and 5.06 respectively), but performed badly in this stringency test, with 147 only 30 and 21 well-predicted T3Es (excluding them from "stringency 2" group) and 35 and 25 148 frameshifted and pseudogenes (excluding them from "stringency 1" group). 149

\section{Gene presence/absence}


151 For each strain, the Table S1 contains the presence/absence scoring for all the 102 Rips and 16

152 hypothetical Rips. We used the prediction data for each strain (see further) as highlighted on the 153 database website (https://iant.toulouse.inra.fr/T3E). Frameshifted genes are rare in well-

154 sequenced genomes. Indeed, out of the 67 strains reported with two scaffolds (corresponding to 155 the expected chromosome and megaplasmid (Salanoubat et al. 2002)), 52 have no frame-shifted 156 genes, and nine only contain one frameshifted gene (see Table S1 for the data). We thus

157 hypothesized that a frameshift is more due to sequencing errors than representing true genomic 158 data. As a consequence, when making a binary scale for scoring the presence/absence of T3Es, 159 we considered all "MULTI" (recently duplicated genes), "OK" (single gene) and "FS" 160 (frameshifted) as "1" (or "present"); when absence "NO" and pseudogene ("PG") were 161 considered as "0" (or “Absent”), this same reasoning was used previously (Peeters et al. 2013a). 162

\section{T3E prediction improvements}

164 We have improved our first T3E prediction pipeline (Peeters et al. 2013a), by adding databases 165 of confirmed T3Es from Xanthomonas spp. (www.xanthomonas.org/t3e.html) and Pseudomonas spp. strains (www.pseudomonas-syringae.org/T3SS-Hops.xls). In order to capture more distantly related Rips, we lowered the tblastN/blastX thresholds (Query coverage per subject $60 \%$, and Percentage of identical matches $60 \%$ ), this was well exemplified by the RipBN case, an AvrRpt2 ortholog clearly present in the CMR15strain (Eschen-Lippold et al. 2016) and also detectable by blast, but not without slightly lower thresholds. We also rewrote some parts of the pipeline in order to speed up the prediction engine. The updated pipeline is outlined in Fig. 1.

172

\section{T3Edb v3 specificities}

174 The new database version is very similar to the previous version (Peeters et al. 2013a). In this 175 new version a set of curated strains ("curated repertoire") is listed on a tab, with a comparison of 176 their T3E repertoire. This set is composed of the following strains: 244 (phylotype I) (Ramesh et 177 al. 2014); GMI1000 (I) (Salanoubat et al. 2002); YC45 (I) (She et al. 2015); CFBP2957 (IIA) 178 (Remenant et al. 2010); CMR15 (III) (Remenant et al. 2010); IPO1609 (IIB) (Gonzalez et al. 179 2011); Molk2 (IIB) (Remenant et al. 2010); Po82 (IIB) (Xu et al. 2011); UW551 (IIB) (Gonzalez 180 et al. 2011); PSI07 (IV) (Remenant et al. 2010); BDBR229 (IV) (Remenant et al. 2011), and R24 181 (IV) (Remenant et al. 2011). 
182 In order to "build profiles" of Rip prediction in different strains to compare the strains and/or to 183 generate multifasta files (of nucleotide or protein sequences of specific Rips), one can now sort 184 the whole set of 155 complete genomes on the different headers available, namely these are: 185 “status (curated or not); "code" (abbreviated name); "synonym”, "species name” (Safni et al. 186 2014); "phylotype"; "plant isolated from"; "assembly size"; "number of contigs"; "number of 187 scaffolds"; "assembly score" (see definitions above).

188

189

\section{Type III secretion dependence}

190 The type III-dependent secretion of Hyp15 and Hyp16, two hypothetical T3Es previously 191 identified in strains GMI1000, CMR15, and PSI07 (Peeters et al. 2013a) was demonstrated in 192 this work. The coding sequences of PSI07_1860 and CMR15v4_mp10184 (both formerly 193 Hyp15), were ordered as DNA synthesis from Sangon (Shanghai, China). RSc3174, from the 194 reference strain GMI1000 (formerly Hyp16) was amplified in two steps. The first PCR was 195 performed using the following primers: Forward : 5'

196 GGAGATAGAACCATGAAAGTCGGCAACCAATC-3' and Reverse 5' 197 CAAGAAAGCTGGGTCTCCACGTGATAAGTTGTAGCG-3', using proof-reading Phusion 198 polymerase using high GC buffer (New England Biolabs). The second PCR was performed using 199 $1 \mu \mathrm{l}$ of the first PCR as matrix and attB universal primers (oNP291

200

201

202 203 204 205 206 207 208 209 210 211 212 5'GGGGACAAGTTTGTACAAAAAAGCAGGCTTCGAAGGAGATAGAACCATG-3' and oNP292 5'-GGGGACCACTTTGTACAAGAAAGCTGGGTC-3', using the same polymerase as the previous PCR with a two step annealing temperature: 10 cycles at $45^{\circ} \mathrm{C}$ and then 25 cycles at 55 ${ }^{\circ} \mathrm{C}$. Then, Rsc3174, PSI07_1860 and CMR15v4_mp10184 were cloned into pDONR207 vector using a BP reaction and in pNP329 using a LR reaction following the instructions of the manufacturer (LifeTechnologies). The final expression vectors were transformed into the $R$. pseudosolanacearum GMI1000 strain and in the $h r c V$ mutant (type III secretion defective mutant, used as a negative control) as previously described (Perrier et al. 2018). In-vitro Secretion assays and Western blot analysis were performed as previously described (Lonjon et al. 2018). 
Results

\section{Curation of 2 new Phylotype I strains and identification of 8 New Rips}

220

221

222

223

224

225

226

227

228

229

230

231

232

233

234

235

236

237

238

239

240

241

242

Because strain GMI1000 was the only curated R. pseudosolanacearum strain in the former RalstoT3Edb (Peeters et al. 2013a), we conducted a manual curation of the Type III effectome in two other R. pseudosolanacearum strains, both differing in host range from GMI1000. Strain Rs10-244 was isolated from chilli pepper (Capsicum annuum) on the Andaman Islands (India) (Ramesh et al. 2014) and strain YC45 was isolated from a monocotyledoneous host, aromatic ginger (Rhizoma kaempferiae) in Southern China (She et al. 2015). Manual curation identified 73 Rip genes ( +1 candidate) in strain YC45 and 77 Rip genes ( +3 candidates) in Rs-10-244. Novel Rip effectors and candidates were identified in these strains (Table 1).

RipBJ was identified by secretome analysis of the GMI1000 strain (R. pseudosolanacearum) (Lonjon et al. 2016). RipBK and RipBL were identified in the process of curation of the strain YC45 (R. pseudosolanacearum), owing to their similarity to HopAM1 (Chang et al. 2005; Goel et al. 2008) and HopAO1 (Chang et al. 2005; Macho et al. 2014). RipBM and RipBO, formerly known as Hyp15 and Hyp16, respectively (Peeters et al. 2013a), were experimentally confirmed to be secreted by the T3SS in GMI1000 (Fig. 2, Fig. S2). RipBN was identified by sequence homology in the strain CMR15 (R. pseudosolanacearum) (Eschen-Lippold et al. 2016). RipBP (homolog to HopW1 (Zumaquero et al. 2010)) was identified in the strain OE1-1 ( $R$. pseudosolanacearum), and RipBQ (homolog to HopK1 (Chang et al. 2005)) in the strain KACC10722 (R. syzygii). RipBP and RipBQ are considered here as Rips by applying the rule of similarity with a known T3E (Peeters et al. 2013a). These two latter Rips have been highlighted in the curated list of strains although none of these curated strains harbor these effectors. This is the same for RipBE which is specific to strain RS1000 (Mukaihara \& Tamura 2009; Peeters et al. 2013a). Table 1 mentions the reference sequences for new Rip genes. Two new hypothetical Rips were also identified; named Hyp17 and Hyp18 with two associated reference sequences 
243 (See Table 1). Considering that in the previous database (Peeters et al. 2013a), some Rips were 244 only represented by pseudogenes, we corrected this by attributing new reference sequences to 245 RipBA (strain Rs-10-244, sequence RS244_c002320), RipBE (strain YC40-M, sequence YC40246 M_00170) and RipP3 (strain Rs-10-244, sequence RS244_c031810).

247

248 Improved Rip-scanning pipeline

249 Thanks to the increased dataset of 102 total Rips (and 16 hypothetical T3Es), on a total of 155 250 genomes (totaling 140 different strains), we were able to generate new effector profiles for the 251 improved prediction of these Rips and candidate Rips in newly available Ralstonia genomes. The 252 "scan your genome" tool is available on the database website. For large dataset analysis, we

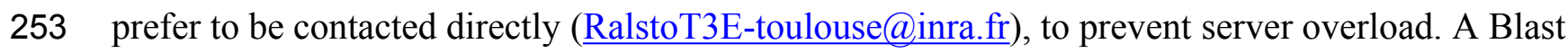
254 tool, as well as all the files and results of predictions for the 155 genomes are also available on 255 our website. A convenient tool is the availability of multifasta files for the nucleotide or protein 256 sequences for a given Rip, containing the genome/strain sequences that one queried for 257 comparison in the first place.

258

259

260

Core effectors

261

We wanted to have a new look at the number of conserved Rips among this new diverse set of strains. As a principle, as more strains are compared, the smaller the core set of Rips will

262 become. In order to have a pertinent set of strains to compare, we decided to limit the core 263 comparisons to the "stringency 2" set of strains (the 84 distinct strains having less than 10 264 pseudogenes or frameshifted genes and, at the same time, more than 50 predicted Rip genes). 265 Fig. 3 shows a phylogenetic tree built using the mutS gene sequence of these 84 strains to be able to judge the relatedness of this set of strains. We are aware of the risk of excluding some strains based on this stringent selection. This could in particular be the case for the known strains that 268 have seen genome reduction and hence have fewer T3Es. This is the case for the Moko disease, or blood disease bacterium BDBR229 (Remenant et al. 2011), and the R. syzygii clove-tree infecting and insect-transmitted R24 strain (Remenant et al. 2011), which each have respectively

27154 and 48 Rip genes (as defined under the "stringency 2" criteria). Moreover, both strains are 272 already left out under "stringency 1" criteria, for having more that 10 (respectively 20 and 12), 273 frameshifted and pseudo genes. 
274 We then decided to use the host of isolation as an interesting criterion to compare strains. Of 275 course there are numerous examples of strains isolated on one host and later shown in laboratory 276 settings to be able to infect other host plants. GMI1000, isolated from tomato (Salanoubat et al. 277 2002), was shown to be very well capable of wilting Medicago truncatula (Vailleau et al. 2007) 278 or Arabidopsis thaliana (Deslandes et al. 1998). As laboratory settings are hard to compare 279 between labs, and as thorough host-compatibility has been done only for a handful of strains, we 280 preferred to stick with the host of isolation information, without excluding that the host range 281 might be much wider for some strains, and restricted for others. We decided to compare the 282 conservation of Rip repertoires among the 84 "stringency 2" strains, classifying them into hosts 283 of isolation; Solanaceae strains ("SOL"), tomato strains ("TOM", 15 strains), Eggplant ("EGG", 2849 strains), potato ("POT", 30 strains) and banana ("BAN", 15 strains). The larger, encompassing 285 category being the Solanaceae group, with 58 strains (for the list of strains see Table S1). Table 2 286 indicates the list, per host-of-isolation category of the core set of Rip genes. For a set of $\mathrm{n}$ total

287 288 289 290 291 292 293 294

295 296 297 298 299 300 301 302 303 strains, we decided to still consider core, the Rip genes present in the interval (n; n-5\%) number of strains. For instance, for the 58 "SOL" strains, the core Rip genes are the ones present in 58 to 55 strains. Obviously, the larger the number of strains, the lower the number of conserved Rips. For instance, for the 9 "EGG" strains, there are 44 strictly conserved Rips (in all 9 strains), whereas there are only 27 conserved Rips in the 15 "BAN" strains (in 14 to 15 strains). Figure 4 show two Venn diagram comparing these sets of conserved Rip between host-of-isolation groups.

The set of 140 strains is evenly spread over the three newly defined Ralstonia species (see Fig. S1 for a mutS phylogeny (Wicker et al. 2012) of the 140 strain/155 genome sequences of this study). One possible caveat is the small number of phylotype III strains (only two strains: CMR15 and CFBP3059), now classified with phylotype I strains among the $R$.

pseudosolanacearum. One interesting way to look at the conservation of Rips is to make specific species groups. The 84 "stringency 2" strains are well spread over the three phylogenetic groups: 38 are $R$. pseudosolanacearum strains (phylotypes I and III), 25 are $R$. solanacearum strains (phylotypes IIA and IIB), and 21 are R. syzygii strains (phylotype IV), see Fig. 3 for the mutS phylogeny of these 84 strains (Wicker et al. 2012). Table 3 represents the Rip distribution among 
304 these three species, together with the conservation in the total set of 84 strains. Figure 5 displays

305 the Venn diagram corresponding to this triple comparison.

306

307

\section{Discussion}

309 In this work, we significantly updated the Ralstonia type III secretion effector database (T3Edb)

310 (Peeters et al. 2013a). This latter work, providing a new nomenclature for these essential

311 virulence proteins was widely accepted and cited by the community. Here, we reported on the

312 curation of new plant pathogenic Ralstonia strains, adding new T3Es to this database. These are

313 represented by the new series from RipBJ to RipBQ, among which both RipBM and RipBO were

314 shown in this work to be indeed secreted by the GMI1000 (R. pseudosolanacearum) T3SS. One

315 of these newly defined Rips, RipBN, was identified for being an ortholog of the Pseudomonas

316 syringae AvrRpt2 T3E (Eschen-Lippold et al. 2016), and recently shown to function similarly in

317 triggering resistance in Ptr1-tomato lines (Mazo-Molina et al. 2019).

318 The newly defined Rip profiles (102 Rips and 16 Hypothetical Rips) were then used to predict

319 the T3E repertoire of the 155 genome sequences available, representing a total of 140 different

320 strains, compared to the 12 genomes previously available. This large set of strains allows us to

321 provide an updated database with a better representation of each of the three phylogenetic clades

322 of this species complex. These are: Phylotypes I and III, or the newly proposed species named

323 R. pseudosolanacearum (Safni et al. 2014), phylotypes IIA and IIB, or R. solanacearum and

324 phylotype IV, or R. syzygii. For a better view of strain relatedness, $m u t S$ phylogenies are

325 displayed in Fig. 3 (set of 84 strains), and in Fig. S1 (all 140 strains). In order to understand the

326 contribution of these T3Es to the virulence of these bacteria on their host plant, it is particularly

327 interesting to analyze which T3Es are conserved among the different strains. Our comparison

328 results highlight two ways to explore these repertoires: either by host plant or by phylogenetic

329 relatedness.

330

331 Ideally, each of the deeply-sequenced and well-annotated strains (the "stringency 2" list of 84

332 strains) should be tested on a panel of host plants in order to define their actual host range. As

333 these data are not available we focused on the host of isolation as a limited but natural host

334 definition factor. This is a strong limitation in this comparison, as it is reported or known (and 
335 shared through personal communications) that some strains are also compatible with other, and

336 sometimes distantly related hosts. We decided to add the published information on the

337 compatibility on other host plants in the Table S1. A few research groups added a significant

338 amount of host-compatibility information for a set of strains (Ailloud et al. 2015; Cho et al.

339 2018; Lebeau et al. 2011). Other groups have performed host-compatibility experiments and

340 shared this information with us, e.g. tobacco strain CQPS-1 (Liu et al. 2017) is also mildly

341 pathogenic on tomato (Personal communication Prof. Ding W.), while the blueberry strains

342 P816, P822 and P824 (Bocsanczy et al. 2019), are very aggressive on tomato (personal

343 communication Dr Norman DJ). In our repertoire comparison, we allow a tolerance of presence

344 for the Rip in the interval of strains between the total number of strains $n$, and $n-5 \%$, this allows

345 to compensate the effect of unequal set of strains to compare. Table 2 and Fig. 4A show that,

346 unsurprisingly strains isolated from Eggplant "EGG", tomato "TOM" and potato "POT", share a

347 significative number of their conserved T3Es (22 shared out of 44 "EGG", 44 "TOM" and 30

348 "POT"), this number is probably largely underestimated as we know that some of these

349 Solanaceae-isolated strains are compatible with other Solanaceae (Lebeau et al. 2011). Another

350 comparison shown (Fig. 4B) is between the "TOM", "POT" and banana "BAN" strains. Here,

351 we can see that there could be more T3Es shared between "BAN" and "TOM" (21 out of 27

352 "BAN" strains) than between "BAN" and "POT" (15 out of 27 "BAN" strains). To evaluate this

353 potential difference, one has to keep in mind that, although banana and Solanaceae are distantly

354 related, it has been shown that 9 out of the 27 "BAN" strains are also compatible with tomato

355 and potato, when only one strain (BDBR229) was shown to be incompatible on these two

356 Solanaceae hosts (Ailloud et al. 2015). When considering all Solanaceae (SOL) as host of

357 isolation (58 strains from the "stringency 2" set of 84 strains), the core set of T3Es (as defined to

358 be present in 55 to 58 strains) is represented by a list of 27 T3Es (see Table 2). It is only when

359 host-compatibility is compared in detail with T3E repertoires that we can start to potentially

360 associate the presence (or the presence of specific alleles) to be required (or deleterious) for

361 specific host-compatibility (Cho et al. 2019; Wang et al. 2016).

362 A second and maybe less ambiguous way to compare lists of conserved T3Es is to group the

363 strains by their phylogenetic origin. Table 3 summarizes the T3Es conserved within each of the

364 three phylogenetic groups of strains (Wicker et al. 2012). These groups are: the 38 strains from

365 phylotypes I and III, or R. pseudosolanacearum; the 25 strains from phylotypes IIA and IIB, or 
$366 R$. solanacearum; and the 21 strains from phylotype IV or R. syzygii ; Fig. 3 displays the mutS

367 phylogeny of these 84 strains. Some strong phylogenetic associated presence/absence can be

368 highlighted, like the systematic presence in $R$. pseudosolanacearum and R. syzygii and

369 systematic absence in $R$. solanacearum of the conserved T3Es RipA2, RipG5 and RipZ. Some

370 T3Es are systematically associated with only one of these phylogenetic groups, like RipC1, RipI,

371 RipAC, RipD with $R$. solanacearum; RipL, RipQ, RipS4 with R. pseudosolanacearum and

372 RipA5, RipM, RipS5, RipAQ with $R$ syzygii. Sixteen (16) T3Es are conserved among the

373 phylogenetic groups (Fig. 5 and Table 3). Eight of them are conserved in the different species:

374 RipB (absent only in R. pseudosolanacearum CQPS-1 (Liu et al. 2017)); RipH2 (absent only in

375 R. pseudosolanacearum RSCM isolated from Cucurbita maxima in China (She et al. 2017));

376 RipR (absent only in $R$ solanacearum UW181, a plantain banana strain (Wicker et al. 2012), and

377 R. syzygii BDB_RUN1347, no host of isolation reported); RipW (absent only in

378 R. pseudosolanacearum strain SL3822 isolated form potato in Korea (Cho et al. 2018); RipAB

379 (absent only in R. pseudosolanacearum strain YC40-M, no host of isolation reported, and

$380 R$. solanacearum strain MolK2 (Remenant et al. 2010)); RipAI (absent only in

$381 R$. pseudosolanacearum strain HA4-1 a Chinese peanut strain); RipAO (absent only in

382 R. pseudosolanacearum strain SL3755 isolated form potato in Korea (Cho et al. 2018)). The only

383 strictly conserved T3E among these 84 strains is RipAJ. Eight others are slightly

384 underrepresented in one species out of the three (number of strains in which the T3E is present is

385 indicated in brackets in Table 3). Among these two (2) are less conserved in

386 R. pseudosolanacearum (Phylotype I and III): RipAN and RipAY; four (4) are less conserved in

387 R. solanacearum (Phylotype II): RipA2, RipG5, RipG6, RipAM; two (2) are less conserved in

388 R. syzygii (Phylotype IV): RipU and RipV1.

389

390

391

392

393 Conclusions

394 This work describes the methods and strains used to build a comprehensive database of the type

395 III effectors (T3Es) from the Ralstonia solanacearum Species Complex (R. solanacearum,

396 R. pseudosolanacearum and R. syzygii). Representing a resource to both study and identify new

Peer] reviewing PDF | (2019:05:37456:1:0:NEW 18 Jun 2019) 
397 398

399

400

401

402

403

404

405

406

407

408

409

410

411

412

413

414

415

416

417

418

419

420

421

422

423

424

425

426

427

428

429

allelic versions of specific T3Es, the database contains all the specific T3E sequences (102 T3Es and 16 hypothetical T3Es in over 155 strains), but also allows to identify new T3E orthologs by scanning DNA sequences (partial, shotgun or complete genomes) from original isolates.

\section{Acknowledgements}

CRRS was funded by grants from Lebanon (the municipality of Nabatieh and the association for scientific orientation and specialization). APM is supported by the Shanghai Center for Plant Stress Biology (Chinese Academy of Sciences) and the Chinese 1000 Talents Program. We also acknowledge the Laboratoire d'Excellence (LABEX) TULIP (ANR-10-LABX-41) for funding. We wish to thanks two anonymous reviewers and David Baltrus for helping use improve this manuscript with their thoughtful comments and suggestions.

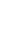

5

6

\footnotetext{
references

Ailloud F, Lowe T, Cellier G, Roche D, Allen C, and Prior P. 2015. Comparative genomic analysis of Ralstonia solanacearum reveals candidate genes for host specificity. BMC Genomics 16:270. 10.1186/s12864-015-1474-8

Bergsma-Vlami M, van de Bilt JLJ, Tjou-Tam-Sin NNA, Westenberg M, Meekes ETM, Teunissen HAS, and Van Vaerenbergh J. 2018. Phylogenetic Assignment of Ralstonia pseudosolanacearum (Ralstonia solanacearum Phylotype I) Isolated from Rosa spp. Plant Dis 102:2258-2267. 10.1094/PDIS-09-17-1345-RE

Bocsanczy AM, Espindola AS, and Norman DJ. 2019. Whole-Genome Sequences of Ralstonia solanacearum Strains P816, P822, and P824, Emerging Pathogens of Blueberry in Florida. Microbiol Resour Announc 8. 10.1128/MRA.01316-18
} 
430 Buttner D. 2016. Behind the lines-actions of bacterial type III effector proteins in plant cells.

431

432

433

434

435

436

437

438

439

440

441

442

443

444

445

446

447

448

449

450

451

452

453

454

455

456

457

458

459

460

461

462

463

464

465

466

467

468

469

470

471

472

473

474

475

476

477

478
FEMS Microbiol Rev 40:894-937. 10.1093/femsre/fuw026

Chang JH, Urbach JM, Law TF, Arnold LW, Hu A, Gombar S, Grant SR, Ausubel FM, and Dangl JL. 2005. A high-throughput, near-saturating screen for type III effector genes from Pseudomonas syringae. Proc Natl Acad Sci U S A 102:2549-2554. 10.1073/pnas.0409660102

Cho H, Song ES, Heu S, Baek J, Lee YK, Lee S, Lee SW, Park DS, Lee TH, Kim JG, and Hwang I. 2019. Prediction of Host-Specific Genes by Pan-Genome Analyses of the Korean Ralstonia solanacearum Species Complex. Front Microbiol 10:506. 10.3389/fmicb.2019.00506

Cho H, Song ES, Lee YK, Lee S, Lee SW, Jo A, Lee BM, Kim JG, and Hwang I. 2018. Analysis of Genetic and Pathogenic Diversity of Ralstonia solanacearum Causing Potato Bacterial Wilt in Korea. Plant Pathol J 34:23-34. 10.5423/PPJ.FT.09.2017.0203

Deslandes L, Pileur F, Liaubet L, Camut S, Can C, Williams K, Holub E, Beynon J, Arlat M, and Marco Y. 1998. Genetic characterization of RRS1, a recessive locus in Arabidopsis thaliana that confers resistance to the bacterial soilborne pathogen Ralstonia solanacearum. Mol Plant Microbe Interact 11:659-667. 10.1094/MPMI.1998.11.7.659

Dillon MM, Thakur S, Almeida RND, Wang PW, Weir BS, and Guttman DS. 2019.

Recombination of ecologically and evolutionarily significant loci maintains genetic cohesion in the Pseudomonas syringae species complex. Genome Biol 20:3. 10.1186/s13059-018-1606-y

Dong X, Lu X, and Zhang Z. 2015. BEAN 2.0: an integrated web resource for the identification and functional analysis of type III secreted effectors. Database (Oxford) 2015:bav064. 10.1093/database/bav064

Eschen-Lippold L, Jiang X, Elmore JM, Mackey D, Shan L, Coaker G, Scheel D, and Lee J. 2016. Bacterial AvrRpt2-Like Cysteine Proteases Block Activation of the Arabidopsis Mitogen-Activated Protein Kinases, MPK4 and MPK11. Plant Physiol 171:2223-2238. 10.1104/pp.16.00336

Goel AK, Lundberg D, Torres MA, Matthews R, Akimoto-Tomiyama C, Farmer L, Dangl JL, and Grant SR. 2008. The Pseudomonas syringae type III effector HopAM1 enhances virulence on water-stressed plants. Mol Plant Microbe Interact 21:361-370. 10.1094/MPMI-21-3-0361

Gomez-Valero L, Rusniok C, Carson D, Mondino S, Perez-Cobas AE, Rolando M, Pasricha S, Reuter S, Demirtas J, Crumbach J, Descorps-Declere S, Hartland EL, Jarraud S, Dougan G, Schroeder GN, Frankel G, and Buchrieser C. 2019. More than 18,000 effectors in the Legionella genus genome provide multiple, independent combinations for replication in human cells. Proc Natl Acad Sci U S A 116:2265-2273. 10.1073/pnas.1808016116

Gonzalez A, Plener L, Restrepo S, Boucher C, and Genin S. 2011. Detection and functional characterization of a large genomic deletion resulting in decreased pathogenicity in Ralstonia solanacearum race 3 biovar 2 strains. Environ Microbiol 13:3172-3185. 10.1111/j.1462-2920.2011.02636.x

Hyatt D, Chen GL, Locascio PF, Land ML, Larimer FW, and Hauser LJ. 2010. Prodigal: prokaryotic gene recognition and translation initiation site identification. $B M C$ Bioinformatics 11:119. 10.1186/1471-2105-11-119

Lebeau A, Daunay MC, Frary A, Palloix A, Wang JF, Dintinger J, Chiroleu F, Wicker E, and Prior P. 2011. Bacterial wilt resistance in tomato, pepper, and eggplant: genetic resources respond to diverse strains in the Ralstonia solanacearum species complex. Phytopathology 101:154-165. 10.1094/PHYTO-02-10-0048 
479

480

481

482

483

484

485

486

487

488

489

490

491

492

493

494

495

496

497

498

499

500

501

502

503

504

505

506

507

508

509

510

511

512

513

514

515

516

517

518

519

520

521

522

523

524

525

526

527

528

529

Liu Y, Tang Y, Qin X, Yang L, Jiang G, Li S, and Ding W. 2017. Genome Sequencing of Ralstonia solanacearum CQPS-1, a Phylotype I Strain Collected from a Highland Area with Continuous Cropping of Tobacco. Front Microbiol 8:974. 10.3389/fmicb.2017.00974

Lonjon F, Peeters N, Genin S, and Vailleau F. 2018. In Vitro and In Vivo Secretion/Translocation Assays to Identify Novel Ralstonia solanacearum Type 3 Effectors. Methods Mol Biol 1734:209-222. 10.1007/978-1-4939-7604-1_17

Lonjon F, Turner M, Henry C, Rengel D, Lohou D, van de Kerkhove Q, Cazale AC, Peeters N, Genin S, and Vailleau F. 2016. Comparative Secretome Analysis of Ralstonia solanacearum Type 3 Secretion-Associated Mutants Reveals a Fine Control of Effector Delivery, Essential for Bacterial Pathogenicity. Mol Cell Proteomics 15:598-613. 10.1074/mcp.M115.051078

Macho AP, Schwessinger B, Ntoukakis V, Brutus A, Segonzac C, Roy S, Kadota Y, Oh MH, Sklenar J, Derbyshire P, Lozano-Duran R, Malinovsky FG, Monaghan J, Menke FL, Huber SC, He SY, and Zipfel C. 2014. A bacterial tyrosine phosphatase inhibits plant pattern recognition receptor activation. Science 343:1509-1512.

10.1126/science.1248849

Mansfield J, Genin S, Magori S, Citovsky V, Sriariyanum M, Ronald P, Dow M, Verdier V, Beer SV, Machado MA, Toth I, Salmond G, and Foster GD. 2012. Top 10 plant pathogenic bacteria in molecular plant pathology. Mol Plant Pathol 13:614-629. 10.1111/j.13643703.2012.00804.x

Mazo-Molina C, Mainiero S, Hind SR, Kraus CM, Vachev M, Maviane-Macia F, Lindeberg M, Saha S, Strickler S, Feder A, Giovannoni J, Smart C, Peeters N, and Martin G. 2019. The Ptr1 locus of Solanum lycopersicoides confers resistance to race 1 strains of Pseudomonas syringae pv. tomato and to Ralstonia pseudosolanacearum by recognizing the type III effectors AvrRpt2/RipBN. Mol Plant Microbe Interact. 10.1094/MPMI-01-19-0018-R

Mukaihara T, and Tamura N. 2009. Identification of novel Ralstonia solanacearum type III effector proteins through translocation analysis of hrpB-regulated gene products. Microbiology 155:2235-2244. 10.1099/mic.0.027763-0

Peeters N, Carrere S, Anisimova M, Plener L, Cazale AC, and Genin S. 2013a. Repertoire, unified nomenclature and evolution of the Type III effector gene set in the Ralstonia solanacearum species complex. BMC Genomics 14:859. 10.1186/1471-2164-14-859

Peeters N, Guidot A, Vailleau F, and Valls M. 2013b. Ralstonia solanacearum, a widespread bacterial plant pathogen in the post-genomic era. Mol Plant Pathol 14:651-662. 10.1111/mpp. 12038

Perrier A, Barberis P, and Genin S. 2018. Introduction of Genetic Material in Ralstonia solanacearum Through Natural Transformation and Conjugation. Methods Mol Biol 1734:201-207. 10.1007/978-1-4939-7604-1_16

Ramesh R, Gaitonde S, Achari G, Asolkar T, Singh NP, Carrere S, Genin S, and Peeters N. 2014. Genome Sequencing of Ralstonia solanacearum Biovar 3, Phylotype I, Strains Rs09-161 and Rs-10-244, Isolated from Eggplant and Chili in India. Genome Announc 2. 10.1128/genomeA.00323-14

Remenant B, Coupat-Goutaland B, Guidot A, Cellier G, Wicker E, Allen C, Fegan M, Pruvost O, Elbaz M, Calteau A, Salvignol G, Mornico D, Mangenot S, Barbe V, Medigue C, and Prior P. 2010. Genomes of three tomato pathogens within the Ralstonia solanacearum species complex reveal significant evolutionary divergence. BMC Genomics 11:379. 10.1186/1471-2164-11-379

Remenant B, de Cambiaire JC, Cellier G, Jacobs JM, Mangenot S, Barbe V, Lajus A, Vallenet D, Medigue C, Fegan M, Allen C, and Prior P. 2011. Ralstonia syzygii, the Blood Disease Bacterium and some Asian R. solanacearum strains form a single genomic species despite divergent lifestyles. PLoS One 6:e24356. 10.1371/journal.pone.0024356

Peer] reviewing PDF | (2019:05:37456:1:0:NEW 18 Jun 2019) 
530

531

532

533

534

535

536

537

538

539

540

541

542

543

544

545

546

547

548

549

550

551

552

553

554

555

556

557

558

559

560

561

562

563

564

565

566

567

568

569

570

571

572

573

574

575

576

577

578

579

580

Safni I, Cleenwerck I, De Vos P, Fegan M, Sly L, and Kappler U. 2014. Polyphasic taxonomic revision of the Ralstonia solanacearum species complex: proposal to emend the descriptions of Ralstonia solanacearum and Ralstonia syzygii and reclassify current R. syzygii strains as Ralstonia syzygii subsp. syzygii subsp. nov., R. solanacearum phylotype IV strains as Ralstonia syzygii subsp. indonesiensis subsp. nov., banana blood disease bacterium strains as Ralstonia syzygii subsp. celebesensis subsp. nov. and R. solanacearum phylotype I and III strains as Ralstonia pseudosolanacearum sp. nov. Int J Syst Evol Microbiol 64:3087-3103. 10.1099/ijs.0.066712-0

Salanoubat M, Genin S, Artiguenave F, Gouzy J, Mangenot S, Arlat M, Billault A, Brottier P, Camus JC, Cattolico L, Chandler M, Choisne N, Claudel-Renard C, Cunnac S, Demange N, Gaspin C, Lavie M, Moisan A, Robert C, Saurin W, Schiex T, Siguier P, Thebault P, Whalen M, Wincker P, Levy M, Weissenbach J, and Boucher CA. 2002. Genome sequence of the plant pathogen Ralstonia solanacearum. Nature 415:497-502. $10.1038 / 415497 a$

Schwartz AR, Potnis N, Timilsina S, Wilson M, Patane J, Martins J, Jr., Minsavage GV, Dahlbeck D, Akhunova A, Almeida N, Vallad GE, Barak JD, White FF, Miller SA, Ritchie D, Goss E, Bart RS, Setubal JC, Jones JB, and Staskawicz BJ. 2015. Phylogenomics of Xanthomonas field strains infecting pepper and tomato reveals diversity in effector repertoires and identifies determinants of host specificity. Front Microbiol 6:535. 10.3389/fmicb.2015.00535

She X, Tang Y, He Z, and Lan G. 2015. Genome Sequencing of Ralstonia solanacearum Race 4, Biovar 4, and Phylotype I, Strain YC45, Isolated from Rhizoma kaempferiae in Southern China. Genome Announc 3. 10.1128/genomeA.01110-15

She X, Yu L, Lan G, Tang Y, and He Z. 2017. Identification and Genetic Characterization of Ralstonia solanacearum Species Complex Isolates from Cucurbita maxima in China. Front Plant Sci 8:1794. 10.3389/fpls.2017.01794

Vailleau F, Sartorel E, Jardinaud MF, Chardon F, Genin S, Huguet T, Gentzbittel L, and Petitprez M. 2007. Characterization of the interaction between the bacterial wilt pathogen Ralstonia solanacearum and the model legume plant Medicago truncatula. Mol Plant Microbe Interact 20:159-167. 10.1094/MPMI-20-2-0159

Wang K, Remigi P, Anisimova M, Lonjon F, Kars I, Kajava A, Li CH, Cheng CP, Vailleau F, Genin S, and Peeters N. 2016. Functional assignment to positively selected sites in the core type III effector RipG7 from Ralstonia solanacearum. Mol Plant Pathol 17:553-564. $10.1111 / \mathrm{mpp} .12302$

Waterhouse RM, Seppey M, Simao FA, Manni M, loannidis P, Klioutchnikov G, Kriventseva EV, and Zdobnov EM. 2017. BUSCO applications from quality assessments to gene prediction and phylogenomics. Mol Biol Evol. 10.1093/molbev/msx319

Wei HL, Chakravarthy S, Mathieu J, Helmann TC, Stodghill P, Swingle B, Martin GB, and Collmer A. 2015. Pseudomonas syringae pv. tomato DC3000 Type III Secretion Effector Polymutants Reveal an Interplay between HopAD1 and AvrPtoB. Cell Host Microbe 17:752-762. 10.1016/j.chom.2015.05.007

Wicker E, Lefeuvre P, de Cambiaire JC, Lemaire C, Poussier S, and Prior P. 2012. Contrasting recombination patterns and demographic histories of the plant pathogen Ralstonia solanacearum inferred from MLSA. ISME J 6:961-974. 10.1038/ismej.2011.160

Xu J, Zheng HJ, Liu L, Pan ZC, Prior P, Tang B, Xu JS, Zhang H, Tian Q, Zhang LQ, and Feng J. 2011. Complete genome sequence of the plant pathogen Ralstonia solanacearum strain Po82. J Bacteriol 193:4261-4262. 10.1128/JB.05384-11

Zumaquero A, Macho AP, Rufian JS, and Beuzon CR. 2010. Analysis of the role of the type III effector inventory of Pseudomonas syringae pv. phaseolicola 1448a in interaction with the plant. J Bacteriol 192:4474-4488. 10.1128/JB.00260-10

Peer) reviewing PDF | (2019:05:37456:1:0:NEW 18 Jun 2019) 
582 Figure legends

583

584 Figure 1. New T3E prediction pipeline.

585

586 Figure 2. RipBM and RipBO are secreted through the T3SS.

587 The wild-type strain and the $h r c V$ mutant were transformed to express a RipBM $\mathrm{CMR}_{55}-3 \mathrm{HA}$,

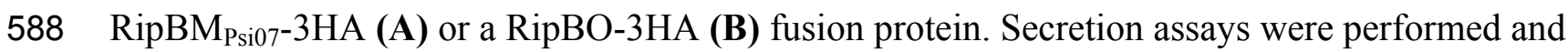
589 total proteins from bacterial pellets and proteins in the supernatants were detected by Western590 Blot.

591

592

Figure 3. mutS alignment and phylogenetic tree of the 84 different strains ("stringency 2 ").

593

A neighbor-joining tree was built using the mutS from Ralstonia pickettii as an outgroup.

594

Bootstrap were performed on 100 replicates, only support higher than $50 \%$ displayed in the

595 consensus tree.

596

597

Figure 4. Venn diagram of conserved T3Es among different sets of "host-of-isolation"

598

defined strains. (A) comparisons of conserved T3Es among "TOM" (host of isolation : tomato),

599 "EGG" (Host of isolation: eggplant) and "POT" (host of isolation : potato). (B) Comparison

600 between "TOM", "POT" and "BAN" (host of isolation: banana). The lists of compared T3Es are 601 visible in Table 2.

602

603

Figure 5. Venn diagram of conserved T3Es among the different phylogenetic clades of

604

strains. Comparison of conserved T3Es between R. pseudosolanacearum (phylotypes I and III), 605 R. solanacearum (phylotypes IIA and IIB), and R. syzygii (Phylotype IV) strains. The lists of 606 compared T3Es are visible in Table 3.

607

608

Supplemental Figure S1. mutS alignment and phylogenetic tree on the set of 140 different

609 strains. A neighbor-joining tree was build using the mutS from Ralstonia pickettii as an

610 outgroup. Bootstrap were performed on 100 replicates, only support higher than $50 \%$ displayed

611 in the consensus tree.

612 
613 Supplemental Figure S2. Uncropped western-blot version of Figure 2.

614 


\section{Table $\mathbf{1}$ (on next page)}

8 new T3E and 2 new Hypothetical T3E identified 
1 Table 1.8 new T3E and 2 new Hypothetical T3E identified

2

\begin{tabular}{|c|c|c|c|c|}
\hline $\begin{array}{l}\text { Proposed T3E } \\
\text { family name }\end{array}$ & $\begin{array}{l}\text { Representative gene } \\
\text { member }\end{array}$ & $\begin{array}{c}\text { Hop/Xop } \\
\text { homologues }\end{array}$ & Functional domain & $\begin{array}{l}\text { Evidence for T3SS- } \\
\text { dependent secretion or } \\
\text { translocation }\end{array}$ \\
\hline RipBJ & GMI1000 RSp0213 & none & & Lonjon et al. 2016 \\
\hline RipBK & YC45 c025370 & HopAM1 & & Chang et al. 2005 \\
\hline RipBL & YC45_m001910 & HopAO1 & $\begin{array}{c}\text { Protein-tyrosine } \\
\text { phosphatase }\end{array}$ & Chang et al. 2005 \\
\hline RipBM & $\begin{array}{l}\text { Psi07 RSPsi07_1860 } \\
\text { (former Hyp15) }\end{array}$ & & $\begin{array}{l}\text { Protein-Ser/Thr } \\
\text { kinase }\end{array}$ & This work \\
\hline RipBN & CMR15v4_30917 & AvrRpt2 & cysteine protease & $\begin{array}{l}\text { Eschen-Lippold et al. } \\
2016\end{array}$ \\
\hline RipBO & $\begin{array}{l}\text { GMI1000 RSc3174 } \\
\text { (former Hyp16) }\end{array}$ & none & & This work \\
\hline RipBP & OE1-1_24290 & $\begin{array}{l}\text { HopW1 }+ \\
\text { homologs in } \\
\text { Xantho }\end{array}$ & $\begin{array}{c}\text { N-term } \\
\text { domain=HopW1 and } \\
\text { C-term= } \\
\text { uncharacterized } \\
\text { protein ABJ99_3552 } \\
\text { [Pseudomonas } \\
\text { syringae pv. } \\
\text { cilantro] }\end{array}$ & Zumaquero et al. 2010 \\
\hline RipBQ & KACC10722_38580 & НорК1/ХорАК & & Chang et al. 2005 \\
\hline Hyp17 & RS244_m000380 & none & & This work \\
\hline Hyp18 & CMR15v4 mp10535 & none & & This work \\
\hline
\end{tabular}

3

4 


\section{Table 2 (on next page)}

List of Type III effectors conserved according to the host of isolation.

The \# strains, indicate the total number of strains analysed and the $5 \%$ tolerance. The numbers in each cell indicate how many strains actually harbor the cognate effector. Grey scale according to conservation between columns. 
Table 2. List of Type III effectors conserved according to the host of isolation. The \# strains, indicate the total number of strains analysed and the $5 \%$ tolerance. The numbers in each cell indicate how many strains actually harbor the cognate effector. Grey scale according to conservation between columns.

\begin{tabular}{|c|c|c|c|c|c|}
\hline & Eggplant & Tomato & Banana & Potato & Solanacea \\
\hline \# strains & 9 & $14-15$ & $14-15$ & $28-30$ & $55-58$ \\
\hline RipA2 & 9 & 15 & & 30 & 58 \\
\hline RipA3 & & 15 & & 28 & 55 \\
\hline RipA4 & & 14 & & & \\
\hline RipA5 & & 14 & 14 & 30 & 55 \\
\hline RipB & 9 & 15 & 15 & 30 & 57 \\
\hline RipC1 & & 14 & 15 & & \\
\hline RipD & & & 15 & & \\
\hline RipE1 & 9 & 14 & 15 & & \\
\hline RipE2 & & & 15 & & \\
\hline RipF1 & & 15 & 14 & 29 & \\
\hline RipG2 & 9 & 14 & & & \\
\hline RipG3 & & & 14 & & \\
\hline RipG4 & 9 & & & & \\
\hline RipG5 & 9 & 15 & 14 & 30 & 58 \\
\hline RipG6 & 9 & 14 & 15 & 30 & 57 \\
\hline RipG7 & & 15 & & 28 & 55 \\
\hline RipH1 & 9 & 14 & 14 & & \\
\hline RipH2 & 9 & 15 & 15 & 30 & 58 \\
\hline RipH3 & 9 & 15 & & 28 & 56 \\
\hline Ripl & & 14 & 15 & & \\
\hline RipJ & 9 & & & & \\
\hline RipL & 9 & & & & \\
\hline RipM & 9 & 15 & & 28 & 55 \\
\hline RipN & 9 & 15 & & & 55 \\
\hline Rip01 & 9 & & & & \\
\hline RipQ & 9 & & & & \\
\hline RipR & 9 & 15 & & 30 & 58 \\
\hline RipS1 & 9 & & & & \\
\hline RipS2 & & 15 & & & \\
\hline RipS3 & & 15 & & & \\
\hline
\end{tabular}




\begin{tabular}{|c|c|c|c|c|c|}
\hline RipS4 & & 14 & & & \\
\hline RipS5 & 9 & 14 & 14 & 29 & 55 \\
\hline RipS6 & 9 & & & & \\
\hline RipU & 9 & 15 & & 30 & 58 \\
\hline RipV1 & 9 & 15 & 15 & 28 & 56 \\
\hline RipW & 9 & 15 & 15 & 29 & 57 \\
\hline RipX & 9 & 15 & & 29 & 57 \\
\hline RipY & 9 & 14 & & & \\
\hline RipZ & 9 & 15 & & 29 & 57 \\
\hline RipAA & 9 & 14 & & 29 & 55 \\
\hline RipAB & 9 & 15 & 14 & 30 & 58 \\
\hline RipAC & 9 & 15 & 15 & & \\
\hline RipAD & & 14 & & 29 & \\
\hline RipAE & 9 & 15 & & & \\
\hline RipAF1 & 9 & & & & \\
\hline RipAl & 9 & 15 & 15 & 30 & 58 \\
\hline RipAJ & 9 & 15 & 15 & 30 & 58 \\
\hline RipAL & & & & 30 & \\
\hline RipAM & 9 & 15 & & 30 & 58 \\
\hline RipAN & & 15 & 15 & 30 & 57 \\
\hline RipAO & 9 & 15 & 15 & 29 & 57 \\
\hline RipAP & 9 & & & & \\
\hline RipAQ & 9 & 15 & & 28 & 56 \\
\hline RipAR & & 14 & 14 & & \\
\hline RipAS & 9 & & & & \\
\hline RipAT & & & 15 & & \\
\hline RipAU & & & 14 & & \\
\hline RipAV & 9 & & & & \\
\hline RipAW & & 14 & & & \\
\hline RipAX1 & & & 14 & & \\
\hline RipAY & & 14 & 15 & 29 & \\
\hline RipAZ1 & 9 & & & & \\
\hline RipBA & 9 & & & & \\
\hline RipBM & 9 & & & & \\
\hline RipTAL & 9 & & & & \\
\hline RipTPS & 9 & 14 & & 29 & 55 \\
\hline $\begin{array}{c}\text { Total } \\
\text { CoreT3Es }\end{array}$ & 44 & 44 & 27 & 30 & 27 \\
\hline
\end{tabular}




\section{Table 3(on next page)}

List of Type III effectors conserved according to the phylogenetic origin.

The \# strains, indicate the total number of strains analysed and the $5 \%$ tolerance. The numbers in each cell indicate how many strains actually harbor the cognate effector. Grey scale according to conservation between columns. 
Table 3. List of Type III effectors conserved according to the phylogenetic origin. The \# strains, indicate the total number of strains analysed and the $5 \%$ tolerance. The numbers in each cell indicate how many strains actually harbor the cognate effector. Grey scale according to conservation between columns.

\begin{tabular}{|c|c|c|c|c|}
\hline & $\begin{array}{c}\text { Phylotype } \\
\text { I and III }\end{array}$ & $\begin{array}{l}\text { Phylotype } \\
\text { IIA and IIB }\end{array}$ & $\begin{array}{c}\text { Phylotype } \\
\text { IV }\end{array}$ & $\begin{array}{c}\text { "stringency } \\
2 "\end{array}$ \\
\hline \# strains & $36-38$ & $24-25$ & $20-21$ & $80-84$ \\
\hline RipA2 & 38 & $(21)$ & 21 & 80 \\
\hline RipA3 & 36 & & 21 & \\
\hline RipA5 & & & 21 & \\
\hline RipB & 37 & 25 & 21 & 83 \\
\hline RipC1 & & 25 & & \\
\hline RipD & & & 20 & \\
\hline RipE1 & & 24 & & \\
\hline RipE2 & & 24 & & \\
\hline RipF1 & & 25 & 20 & \\
\hline RipF2 & & 24 & & \\
\hline RipG2 & 36 & & & \\
\hline RipG4 & 38 & 24 & & \\
\hline RipG5 & 38 & (23) & 21 & 82 \\
\hline RipG6 & 37 & (23) & 21 & 81 \\
\hline RipG7 & 37 & 24 & & \\
\hline RipH1 & & & 20 & \\
\hline RipH2 & 36 & 25 & 21 & 82 \\
\hline RipH3 & 36 & & & \\
\hline RipH4 & & & 20 & \\
\hline Ripl & & 25 & & \\
\hline RipL & 38 & & & \\
\hline RipM & & & 21 & \\
\hline RipN & & & 20 & \\
\hline Rip01 & & 24 & & \\
\hline RipQ & 38 & & & \\
\hline RipR & 38 & 24 & 20 & 82 \\
\hline RipS2 & 36 & & & \\
\hline RipS4 & 38 & & & \\
\hline RipS5 & & & 21 & \\
\hline RipS6 & 37 & & & \\
\hline
\end{tabular}




\begin{tabular}{|c|c|c|c|c|}
\hline RipU & 38 & 25 & (18) & 81 \\
\hline RipV1 & 38 & 25 & (19) & 82 \\
\hline RipV2 & & & 20 & \\
\hline RipW & 37 & 25 & 21 & 83 \\
\hline RipX & & & 21 & \\
\hline RipY & & & 20 & \\
\hline RipZ & 38 & & 21 & \\
\hline RipAB & 37 & 24 & 21 & 82 \\
\hline RipAC & & 25 & & \\
\hline RipAD & & 25 & & \\
\hline RipAE & & 24 & & \\
\hline RipAF1 & 36 & & & \\
\hline RipAl & 36 & 25 & 21 & 82 \\
\hline RipAJ & 38 & 25 & 21 & 84 \\
\hline RipAK & 36 & & & \\
\hline RipAM & 38 & (23) & 21 & 82 \\
\hline RipAN & (35) & 25 & 21 & 81 \\
\hline RipAO & 36 & 25 & 21 & 82 \\
\hline RipAP & 36 & 25 & & \\
\hline RipAQ & & & 21 & \\
\hline RipAS & 36 & & & \\
\hline RipAU & & & 20 & \\
\hline RipAV & 36 & & & \\
\hline RipAY & (35) & 25 & 20 & 80 \\
\hline RipAZ1 & 36 & & 20 & \\
\hline RipBF & & & 20 & \\
\hline T3E_Hyp1 & & & 20 & \\
\hline $\begin{array}{c}\text { Total Core } \\
\text { T3Es }\end{array}$ & 31 & 25 & 32 & 16 \\
\hline
\end{tabular}


Figure 1

T3E prediction pipeline 


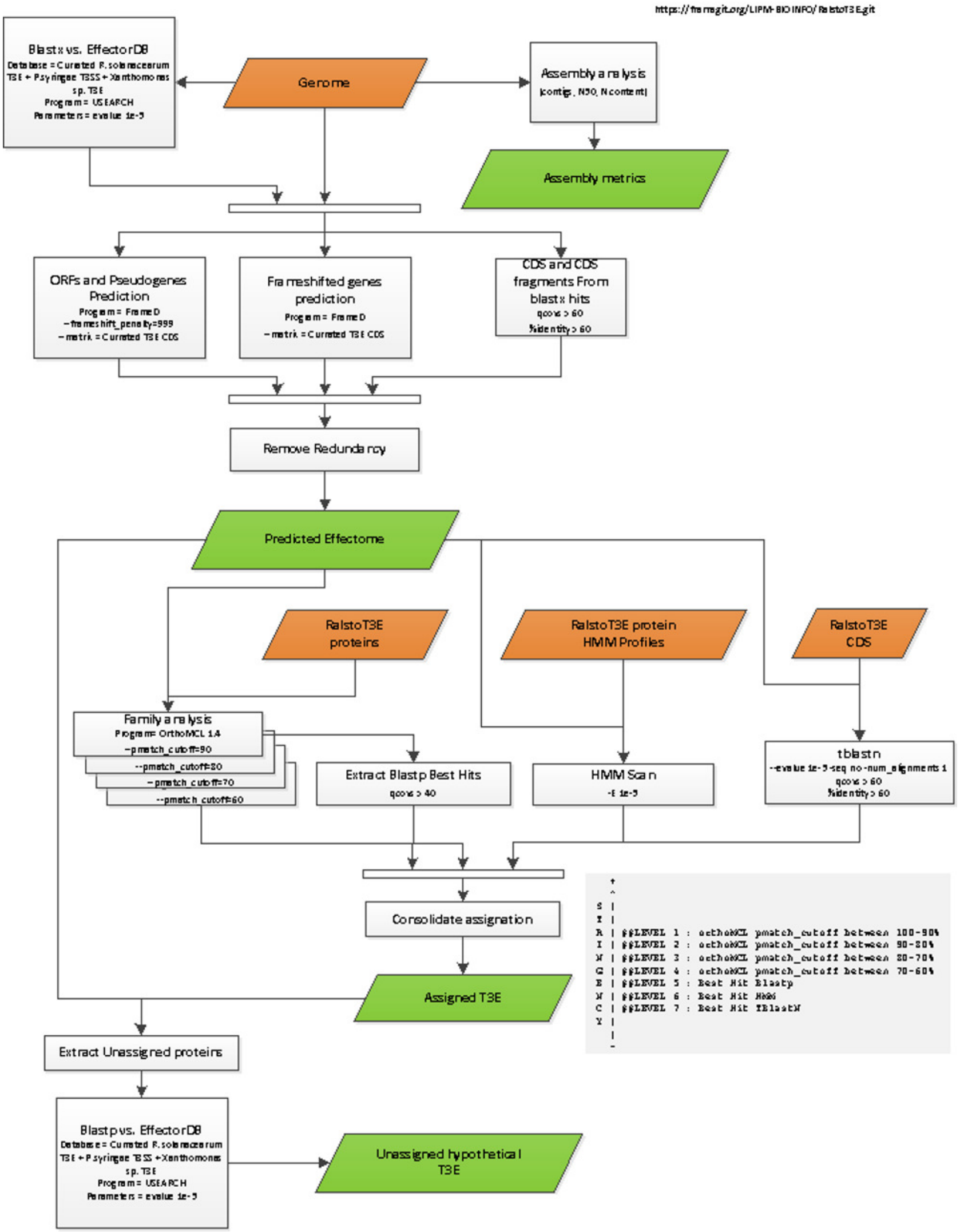

Pipeline: T3E v $\boldsymbol{B}$

sebastien.carrere@inra.fr

LIPM INRA/CNRS

March 2019

Bust $x$ vs. EffectorD

cot torse = C urutzd R. sob mectorum

Assembly a ra lysis 
Figure 2

RipBM and RipBO are secreted through the T3SS

The wild-type strain and the $h r c V$ mutant were transformed to express a $\operatorname{RipBM}_{\text {CMR15 }^{-}}-3 \mathrm{HA}$, RipBM $_{\mathrm{Psi0}}-3 \mathrm{HA}$ (A) or a RipBO-3HA (B)fusion protein. Secretion assays were performed and total proteins from bacterial pellets and proteins in the supernatants were detected by Western-Blot. Uncropped western-blot are displayed on Fig. S2 
A

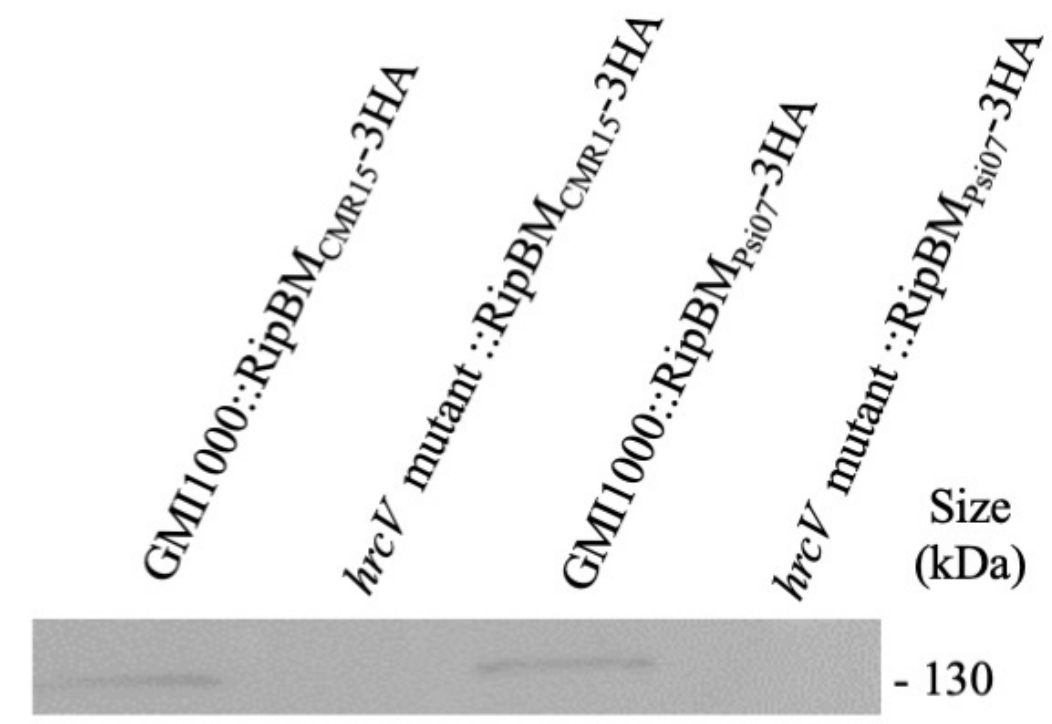

\section{BACTERIAL PELLETS}

B

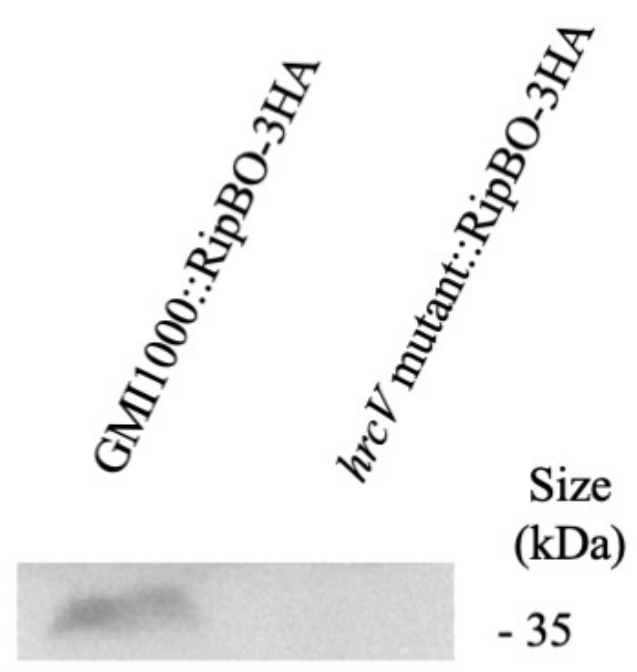

BACTERIAL PELLETS

$-35$ 
Figure 3

mutS alignment and phylogenetic tree on the set of 84 different strains.

A neighbor-joining tree was build using the mutS from Ralstonia pickettii as an outgroup.

Bootstrap were performed on 100 replicates, only support higher than $50 \%$ displayed in the consensus tree.

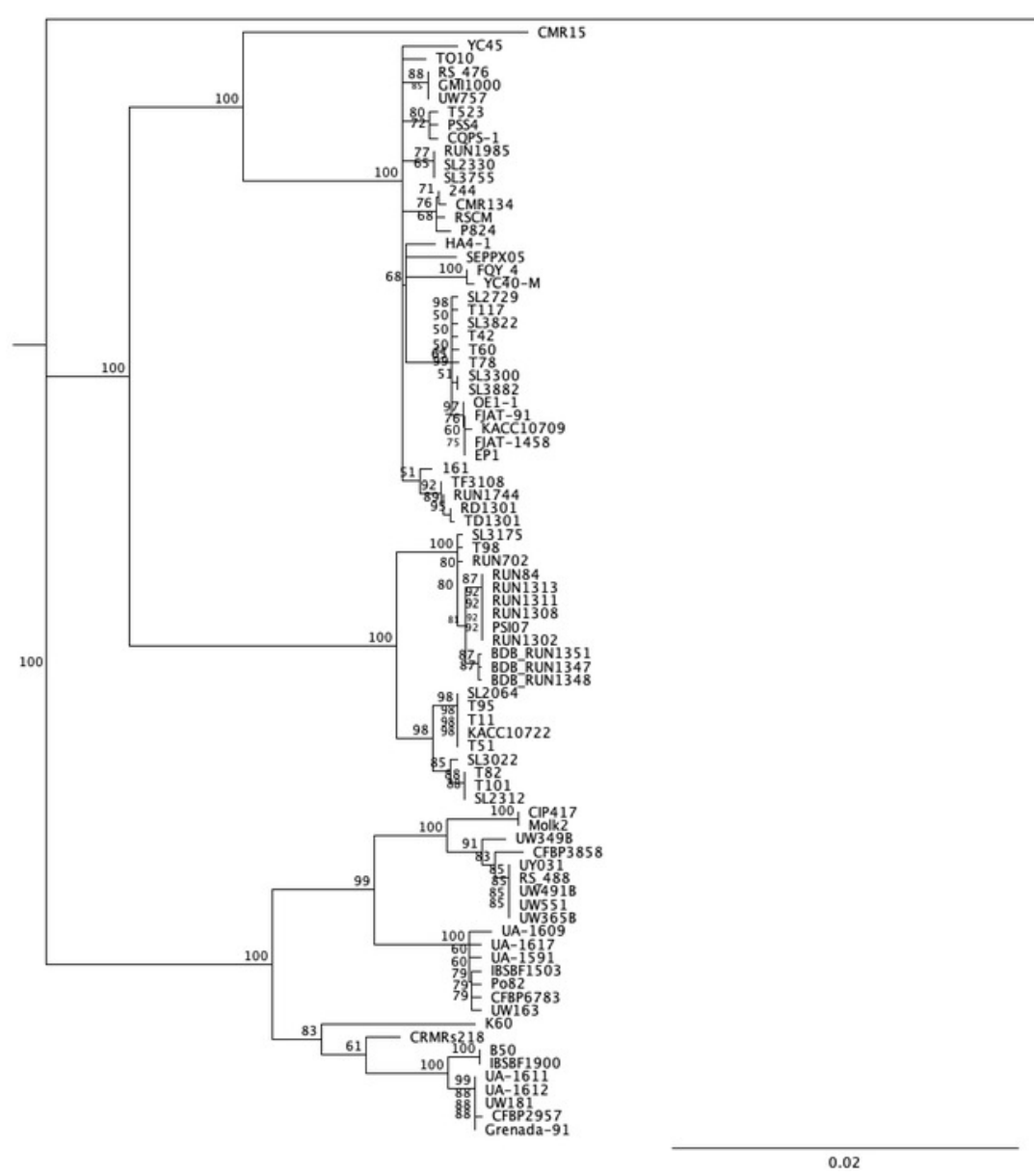




\section{Figure 4}

Venn diagram of conserved T3Es among different sets of "host-of-isolation" defined strains

(A) comparisons of conserved T3Es among "TOM" (host of isolation : tomato), "EGG" (Host of isolation: eggplant) and "POT" (host of isolation : potato). (B)Comparison between "TOM", "POT" and "BAN" (host of isolation: banana). The lists of compared T3Es are visible in Table

2.
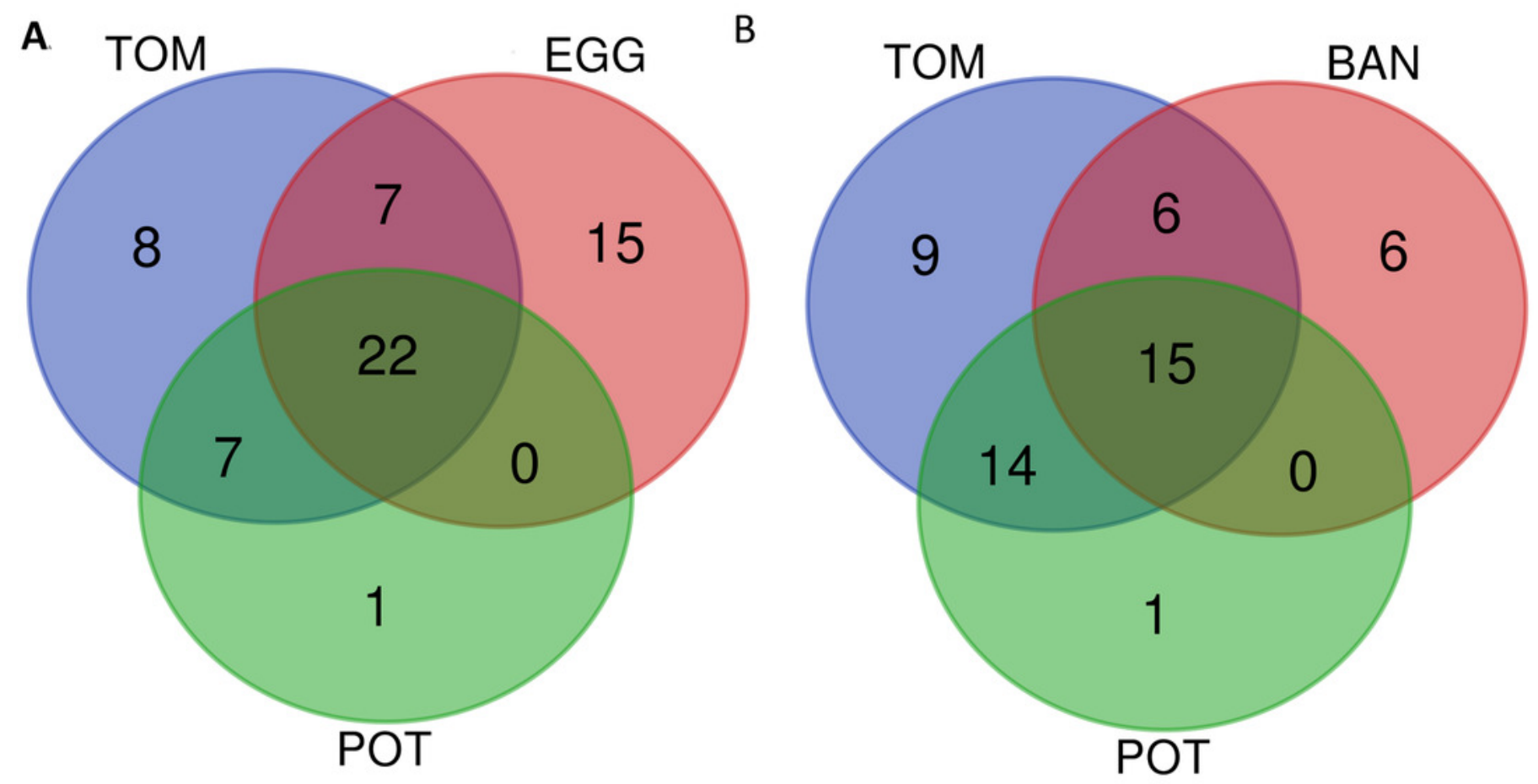
Figure 5

Venn diagram of conserved T3Es among the different phylogenetic clades of strains.

Comparison of conserved T3Es between $R$. pseudosolanacearum (phylotypes I and III), $R$. solanacearum (phylotypes IIA and IIB), and R. syzygii (Phylotype IV) strains. The lists of compared T3Es are visible in Table 3. 


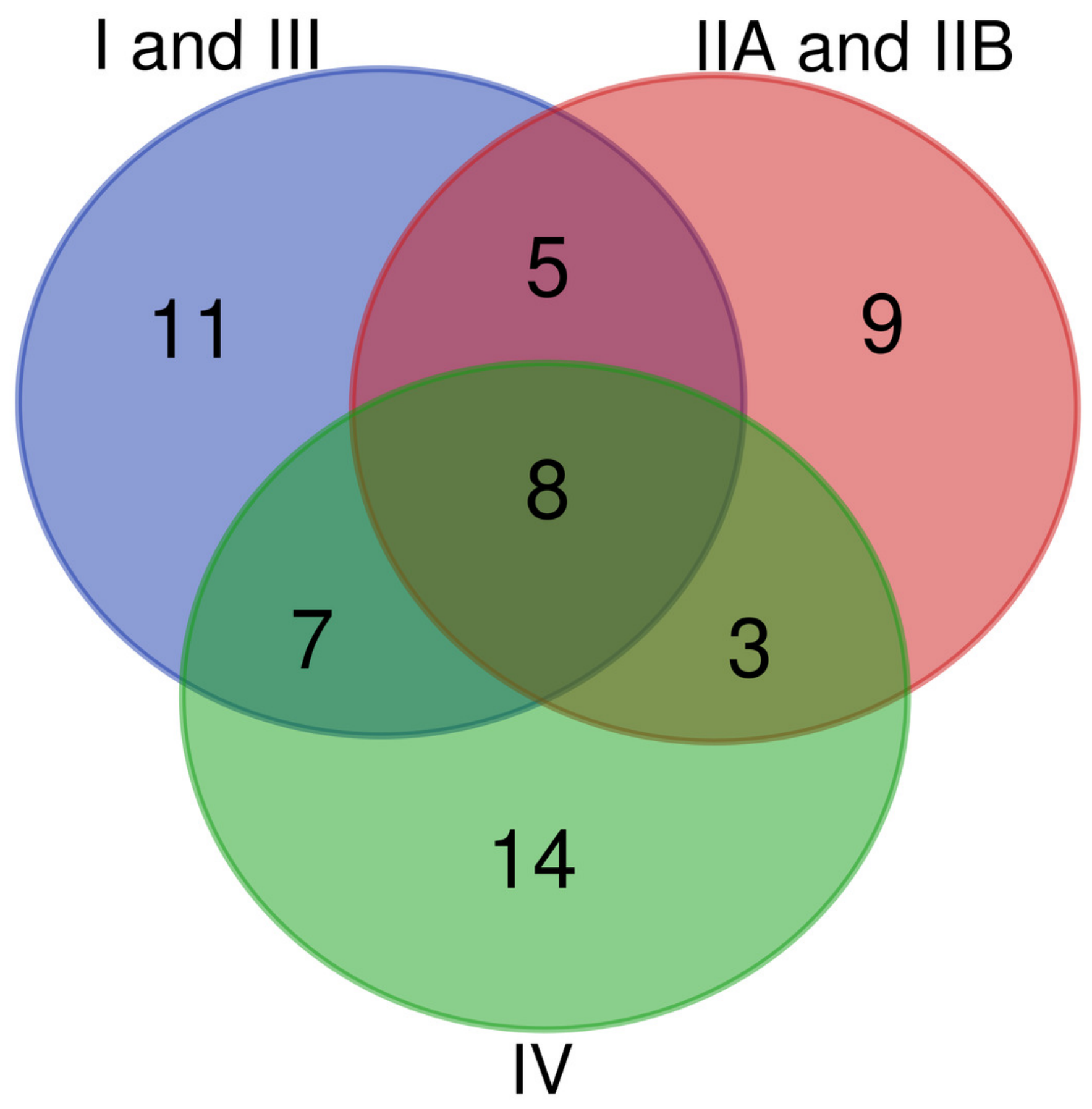

